\title{
Transpancreatic sphincterotomy has a higher cannulation success rate than needle-knife precut papillotomy - a meta-analysis
}

\author{
Authors \\ Áron Vincze ${ }^{1}$ \\ Institutions \\ 1 Division of Gastroenterology, First Department of \\ Medicine, University of Pécs, Pécs, Hungary \\ 2 Institute for Translational Medicine, University of Pécs, \\ Pécs, Hungary \\ 3 Institute of Bioanalysis, University of Pécs, Pécs, \\ Hungary \\ 4 Hungarian Academy of Sciences - University of Szeged, \\ Momentum Gastroenterology Multidisciplinary \\ Research Group, Szeged, Hungary \\ 5 First Department of Paediatrics, Semmelweis University, \\ Budapest, Hungary \\ 6 Heim Pál Children's Hospital, Budapest, Hungary \\ 7 First Department of Surgery, Semmelweis University, \\ Budapest, Hungary
}

Dániel Pécsi ${ }^{1,2}$, Nelli Farkas ${ }^{3}$, Péter Hegyi ${ }^{1,2,4}$, Márta Balaskó2 ${ }^{2}$, József Czimmer ${ }^{1}$, András Garami ${ }^{2}$, Anita Illés ${ }^{1}$, Dóra Mosztbacher ${ }^{5}$, Gabriella Pár ${ }^{1}$, Andrea Párniczky ${ }^{6}$, Patrícia Sarlós ${ }^{1}$, Imre Szabó ${ }^{1}$, Kata Szemes ${ }^{1}$, Ákos Szűcs ${ }^{7}$,

submitted 15.1.2017

accepted after revision 20.4.2017

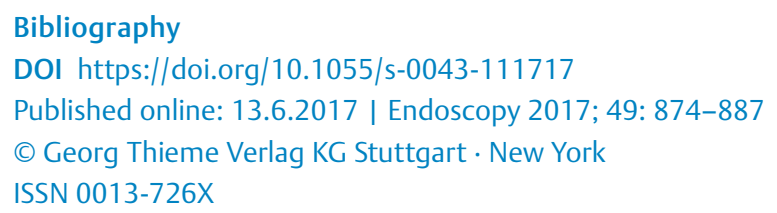

Corresponding author

Áron Vincze, MD, PhD, Division of Gastroenterology , First Department of Medicine, University of Pécs , Ifjúság u. 13, H-7624, Hungary

vincze.aron@pte.hu

$\circledast$ Fig. e2-e5, Table e1,

Online content viewable at:

https://doi.org/10.1055/s-0043-111717

\section{ABSTRACT}

Background and aim While many studies have discussed the different cannulation techniques used in patients with difficult biliary access, no previous meta-analyses have compared transpancreatic sphincterotomy (TPS) to other advanced techniques. Therefore, we aimed to identify all studies comparing the efficacy and adverse event rates of TPS with needle-knife precut papillotomy (NKPP), the most commonly used technique, and to perform a meta-analysis. Methods The Embase, PubMed, and Cochrane databases were searched for trials comparing the outcomes of TPS with NKPP up till December 2016. A meta-analysis focusing on outcome (cannulation success, post-endoscopic retrograde cholangiopancreatography (ERCP) pancreatitis (PEP), post-procedural bleeding, and total adverse events) was performed. The population, intervention, comparison, outcome (PICO) format was used to compare these cannulation approaches. Five prospective and eight retrospective studies were included in our meta-analysis.

Results NKPP has a significantly lower success rate (odds ratio [OR] 0.50, $P=0.046$; relative risk [RR] 0.92, $P=0.03$ ) and a higher rate of bleeding complications (OR 2.24, $P=$ 0.02; RR 2.18, $P=0.02$ ) than TPS. However, no significant differences were found in PEP (OR 0.79, $P=0.24$; RR 0.80, $P=0.19$ ), perforation (risk difference $[R D] 0.01, P=0.23$ ), or total complication rates (OR 1.22, $P=0.44$; RR 1.17, $P=$ $0.47)$.

Conclusion While TPS has a higher success rate in difficult biliary access and causes less bleeding than NKPP, there are no differences in PEP, perforation, or total complication rates between the two approaches. We conclude that TPS, in the hands of expert endoscopists, is a safe procedure, which should be used more widely in patients with difficult biliary access.

\section{Introduction}

Endoscopic retrograde cholangiopancreatography (ERCP) is a therapeutic modality used frequently for the management of most pancreatobiliary disorders. Selective cannulation of the common bile duct (CBD) is required for most indications, and is followed by sphincterotomy and further therapeutic inter- ventions. Successful biliary cannulation is easily achieved in most patients with a few cannulation attempts in the first few minutes of the procedure; however, the initial attempts are not successful in $10 \%-20 \%$ of patients with a native major papilla, depending on the definition of difficult biliary access.

In such patients with difficult biliary cannulation, advanced cannulation techniques are used to facilitate biliary access. Dif- 
ficult cannulation, prolonged cannulation attempts, and advanced techniques are known to increase the risk of adverse effects (post-ERCP pancreatitis (PEP), bleeding, perforation, and cholangitis, among others). The new guideline issued by the European Society of Gastrointestinal Endoscopy (ESGE) provides practical advice on achieving successful cannulation while minimizing the associated risk [1]. The success rate for cannulation may exceed $95 \%$ when using these advanced techniques, while the adverse event rate should remain below $5 \%$, according to the recommended new standards of ERCP [2].

Difficult biliary access is defined in the ESGE guideline as more than five contacts with the papilla while attempting to cannulate, more than 5 minutes spent attempting to cannulate after visualization of the papilla, or more than one unintended pancreatic duct cannulation or opacification [1]. Another new international consensus defines difficult biliary access similarly, but extends the time limit for the standard cannulation technique to 10 minutes [3].

The algorithm recommended in such patients, when the guidewire cannot be inserted into the pancreatic duct, is needle-knife precut papillotomy (NKPP) or fistulotomy (NKF) first. In the case of unintentional pancreatic guidewire (PGW) insertion PGW-assisted cannulation is recommended. The guidewire is kept in the pancreatic duct, and cannulation of the bile duct is attempted by injecting contrast material (single-guidewire technique) or with a second guidewire (double-guidewire [DGW] cannulation). If biliary access is still not possible, transpancreatic biliary sphincterotomy (TPS) can be performed over the pancreatic wire with a standard sphincterotome to expose the biliary orifice.

TPS is a relatively new and underutilized technique, first described by Goff et al. [4], with limited outcome data. One advantage of this method is that the depth of incision is better controlled by the slow pullback of a traction-type sphincterotome in making the incision toward the 11-o'clock position to the direction of the CBD than with the free-hand needle-knife technique. Another advantage is that the sphincterotome does not need to be changed to a needle-knife. In certain types of papillary tracts (small, flat, intradiverticular papilla, or the presence of a small oral protrusion), TPS can be performed more safely than NKPP or NKF. However, for a protruding or swollen papilla, NKPP or NKF may be a more appropriate approach [5].

The alternatives to TPS, needle-knife precut techniques (NKF or NKPP), are the more frequently used. Early precut papillotomy is recommended within 5-10 minutes after the start of the procedure to decrease the PEP rate and, according to a recent review and meta-analysis [6], NKF seems to be better than NKPP. While the use of these advanced cannulation techniques can increase the success rate for CBD cannulation, they also have the potential to significantly increase the adverse event rate.

TPS and other precut techniques have not been compared in any previous meta-analysis. Our aim was, therefore, to identify all studies that compared the efficacy and adverse event rate of TPS and NKPP, and to perform a meta-analysis focusing on the published outcomes for the use of these methods.

\section{Methods}

\section{Literature review}

A meta-analysis was performed using the population, intervention, comparison, outcome (PICO) format. The selected studies had looked at: $(P)$ patients with various indications for ERCP who had difficult biliary access; (I and C) who were managed with TPS or NKPP; with the outcomes (O) being successful biliary cannulation, PEP, post-procedural bleeding, and total adverse event rate.

The electronic databases of Embase, PubMed, and the Cochrane Library were systematically searched for relevant studies. The systematic review was conducted following the Preferred Reporting Items for Systematic Reviews and Meta-Analysis (PRISMA) guidelines ( $>$ Table e1; available online) [7]. All articles comparing TPS and NKPP were searched irrespective of the study design, including randomized prospective, non-randomized prospective, and retrospective studies. There were no restrictions applied regarding the year of publication, language, age, sex, or otherwise. Embase, PubMed, and the Cochrane Library were searched for synonyms of TPS, which are interchangeably used in the literature [8]. The search included the terms "transpancreatic septotomy" OR "transpancreatic sphincterotomy" OR "transpancreatic septostomy" OR "transpancreatic precut sphincterotomy" OR "pancreatic sphincterotomy" OR "transpancreatic papillary septotomy" OR "transpancreatic sphincter precut" OR "transpancreatic duct precut" OR "pancreatic sphincter precutting" OR "pancreatic precut sphincterotomy" OR "transpancreatic precut septotomy” OR "transpancreatic precut septostomy" OR "pancreatic septotomy” OR "pancreatic septostomy” OR "pancreatic precut” OR "transpancreatic precut" OR "transpancreatic".

The latest date searched was 9 December 2016, which yielded 453, 306, and 30 articles in the Embase, PubMed, and Cochrane databases, respectively. An independent eligibility assessment was performed by each author, and disagreements were resolved by consensus. Duplicates, repeated publications, publications available only in abstract form, and review papers were excluded. The articles selected were published in English and compared the success and adverse event rates for the different treatment groups retrospectively or prospectively ( $\triangleright$ Fig. 1). Finally, 13 relevant full-text articles, both prospective and retrospective studies, were included in the quantitative synthesis of this meta-analysis.

The investigators extracted the data from each publication independently (number of subjects, method of cannulation, success rate, and different adverse event rates), and two investigators (D.P. and Á.V.) then validated these data. Disagreements were discussed and resolved by consensus. This meta-analysis has not been registered or published previously.

\section{Quality assessment of the studies included}

Randomized trials were assessed with the method described by Jadad et al. [9], while non-randomized studies were evaluated according to the Methodological Index for Non-Randomized Studies (MINORS) [10]. Two investigators (D.P. and Á.V.) asses- 


\section{Synonyms used: \\ "transpancreatic septotomy" or "transpancreatic sphincterotomy" or "transpancreatic septostomy" or "transpancreatic precut sphincterotomy" or "pancreatic sphincterotomy" or "transpancreatic papillary septotomy" or "transpancreatic sphincter precut" or "transpancreatic duct precut" or "pancreatic sphincter precutting" or "pancreatic precut sphincterotomy" or "transpancreatic precut septotomy" or "transpancreatic precut septostomy" or "pancreatic septotomy" or "pancreatic septostomy" or "pancreatic precut" or "transpancreatic precut" or "transpancreatic"}

789 records identified through database searching: Embase 453, PubMed 306, Cochrane library 30

349 records screened after duplicates removed

286 articles excluded as title and/or abstract not relevant

63 publications assessed for eligibility

50 publications excluded:

- Review or meta-analysis 14

- Other types of intervention 35

- Only available as abstract 1

13 studies included for qualitative synthesis

13 studies included in quantitative synthesis (meta-analysis)

Fig. 1 Flow diagram of the literature search.

sed the quality of each study included. Disagreements regarding the scoring were resolved by consensus.

\section{Statistical methods}

Pooled odds ratios (ORs), relative risks (RRs), and their 95\% confidence intervals (Cls) were calculated to compare the rates of success, PEP, bleeding, and total complications for the different cannulation techniques. The risk difference (RD) was calculated to compare the perforation rates to avoid overestimation because OR or RR calculations would exclude those studies where zero perforations were reported. In the case of a homogeneous subset of studies, we used the fixed-effect model described by Mantel and Haenszel [11]. The random-effect model of DerSimonian and Laird [12] was used when we pooled retrospective and prospective studies.

Heterogeneity was tested with two methods, namely the Cochrane's $Q$ and the $l^{2}$ statistics. The $Q$ test was computed by summing the squared deviations of each study's estimate from the overall meta-analysis estimate; $P$ values were obtained by comparing the statistical results with a $X^{2}$ distribution with $k-1$ degrees of freedom (where $k$ was the number of studies). A $P$ value of less than 0.05 was considered suggestive of significant heterogeneity. The $I^{2}$ statistic represents the percentage of the total variability across studies that is due to heterogeneity. $I^{2}$ values of $25 \%, 50 \%$, and $75 \%$ corresponded to low, moderate, and high degrees of heterogeneity, respectively, based on Cochrane's handbook [13].

Publication bias was examined by visual inspection of funnel plots, in which the standard error (SE) was plotted against the net change of outcome (i.e. success rate, complication rates) for each study.

Meta-analytic calculations were performed with Comprehensive MetaAnalysis software Version 3 (Biostat, Inc., Englewood, New Jersey, USA).

\section{Results}

\section{Description of the studies selected}

Five prospective studies [14-18] and eight retrospective studies [19-26] were identified during our search. Only two studies among the prospective studies were randomized, but neither of these was blinded ( $\downarrow$ Table 2 ). All of the studies provided data on success rates. PEP rate, bleeding rate, and total adverse event rate were not specified in the TPS group in one study, where TPS was performed sequentially after failed DGW cannulation [18]. A second study had the same sequential design [16]. A separate analysis was performed where these two studies were excluded, and we performed another separate analysis with the prospective studies.

The Jadad scoring system (where 0 means very poor and 5 means rigorous reporting) [9] was used to assess the two randomized studies. One of these [14] received only one point, which was because of the poor reporting of the randomization procedure and the lack of double blinding (which is impossible to carry out in endoscopic interventional trials). The other randomized trial [17] received three points because the randomization procedure was appropriately reported ( $\downarrow$ Table 2 ).

The non-randomized studies were assessed using the MINORS score, in which the maximum score for comparative studies is 24 [10]. Eight of the eleven studies received a medium score of 14-16, two trials received higher scores [18, 26], while only one got an underwhelming 10 points [20] for several weaknesses (inclusion of non-consecutive patients, more than $5 \%$ loss to follow-up, non-equivalent groups, etc.) (> Table 2 ).

Funnel plot asymmetry tests were used to detect publication bias. No asymmetry was detected in the assessments of cannulation success rate and PEP rate, while there was asymmetry in the plots of bleeding and total complication rates ( $\mathbf{F i g s . e 2 ~ - ~}$ e5; available online). 
- Table 2 Characteristics of studies comparing NKPP and TPS that were included in the meta-analysis.

\begin{tabular}{|c|c|c|c|c|c|}
\hline \multirow[t]{2}{*}{ Study } & \multirow[t]{2}{*}{ Study design } & \multicolumn{2}{|c|}{ Quality of study } & \multicolumn{2}{|c|}{$\begin{array}{l}\text { Number of included patients in the } \\
\text { different treatment groups }\end{array}$} \\
\hline & & $\begin{array}{l}\text { Jadad scale }^{1} \\
(0-5)\end{array}$ & $\begin{array}{l}\text { MINORS² } \\
(0-24)\end{array}$ & NKPP & TPS \\
\hline Catalano MF, 2004 [14] & Prospective, randomized & 1 & - & 32 & 31 \\
\hline Espinel-Díez J, 2013 [15] & Prospective, non-randomized & - & 16 & 74 & 125 \\
\hline Zang J, 2014 [17] & Prospective, randomized & 3 & - & 76 & 73 \\
\hline Kim CW, 2015 [16] & $\begin{array}{l}\text { Prospective, non-randomized, } \\
\text { sequential }\end{array}$ & - & 16 & 58 & 38 \\
\hline Zou XP, 2015 [18] & $\begin{array}{l}\text { Prospective, non-randomized, } \\
\text { sequential }\end{array}$ & - & 22 & 20 & 25 \\
\hline Horiuchi A, 2007 [21] & Retrospective & - & 14 & 30 & 48 \\
\hline Kapetanos D, 2007 [23] & Retrospective & - & 14 & 15 & 40 \\
\hline Halttunen ], 2009 [20] & Retrospective & - & 10 & 157 & 262 \\
\hline Wang P, 2010 [26] & Retrospective & - & 18 & 76 & 140 \\
\hline Chan CHY, 2012 [19] & Retrospective & - & 16 & 66 & 53 \\
\hline Katsinelos P, 2012 [24] & Retrospective & - & 14 & 129 & 67 \\
\hline Miao L, 2015 [25] & Retrospective & - & 16 & 33 & 36 \\
\hline Huang C, 2016 [22] & Retrospective & - & 14 & 46 & 34 \\
\hline \multicolumn{6}{|c|}{$\begin{array}{l}\text { MINORS, Methodological Index for Non-Randomized Studies. } \\
1 \text { Jadad scale: } 0=\text { very poor, } 5=\text { rigorous. Jadad AR et al. [9]. } \\
2{ }^{2} \text { MINORS: } 12 \text { items are scored }(0=\text { not reported; } 1=\text { reported, but inadequate; } 2=\text { reported and adequate). The global ideal score is } 16 \text { for non-comparative studies } \\
\text { and } 24 \text { for comparative studies. Slim K et al. [10]. }\end{array}$} \\
\hline
\end{tabular}

Six out of the thirteen studies reported that there was no difference in the sex and age distribution between the NKPP and TPS groups $[17,19,21,24-26]$ ( $\triangleright$ Table 3 ). The other studies reported the male/female ratio and the mean age only for all of the involved patients together. The mean ages of the patient groups varied between 49 and 79 years in the analyzed studies. The number of women was more than double the number of men in the study of Huang et al. [22]; one study did not report these data [20]; while all the other studies reported nearly equal sex distribution ( $>$ Table 3 ).

Six of the analyzed studies [17, 19, 21, 24-26] also compared the indications for ERCP in the NKPP and TPS groups; only one study [24] showed significant differences for some of the indications. The indications were not separately analyzed in the other studies, but in general there were no major differences between the studies ( $>$ Table 3 ).

The experience of the endoscopist performing the different advanced cannulation techniques was not reported in three studies $[20,21,25]$; among these, only one study was carried out in a center with lower case volume (approximately 200 ERCPs/year) [21]. Experienced endoscopists performed the procedure in the other studies, although one study reported trainee involvement at the initial cannulation attempt [19], and another stated that approximately one-quarter of the interventions were performed by endoscopists with lower caseloads ( $\leq 3$ ERCPs/week) [26] ( $\triangleright$ Table 3 ).
NKPP was performed in those patients where the pancreatic duct was not accessible in four studies $[16,18,20,26]$. TPS or NKPP was randomly selected in three studies $[14,17,25]$, while it was left to the preference of the endoscopist in the other studies.

\section{Cannulation success}

Four studies found that TPS was significantly better for cannulation success $[15,17,20,24]$; one study showed just a tendency toward a better cannulation rate for TPS [14]; while no differences were found in the other studies.

Our data analysis allowed us to conclude that NKPP is significantly inferior to TPS with regard to cannulation success in terms of both OR $(\mathrm{OR} 0.50,95 \% \mathrm{Cl} 0.25-0.99 ; P=0.046 ; \mathrm{n}=$ 812 vs. $972 ; Q=50.21$, degrees of freedom [df(Q)] 12; $P<$ $0.001 ; R^{2}=76.10 \%$; Fig. 6) and RR (RR 0.92, $95 \% \mathrm{Cl} 0.85-$ 0.99; $P=0.03$; $>$ Table 4). The difference was even more significant when the meta-analysis was carried out using data from the prospective studies only [14-18]. In this comparison, the OR was $0.43(95 \% \mathrm{Cl} 0.26-0.72 ; P=0.001 ; \mathrm{n}=260$ vs. $292 ; Q=$ 4.29, $\mathrm{df}(\mathrm{Q}) 4 ; P=0.37 ; P^{2}=6.85 \%$; Fig. 7). The inferiority was also seen with a similar level of significance when RR values were calculated in the comparison of NKPP and TPS (RR 0.87, $95 \% \mathrm{Cl} 0.82-0.94 ; P<0.001 ;>$ Table 4).

A separate analysis was performed that excluded the studies with sequential design. In this case, the difference between the 


\begin{tabular}{|c|c|c|c|c|c|c|c|c|}
\hline Uัँ & 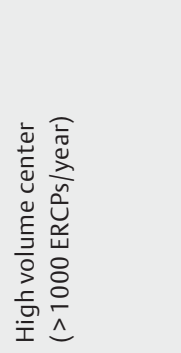 & 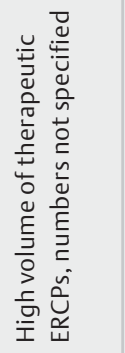 & 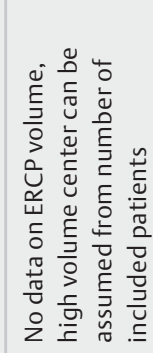 & 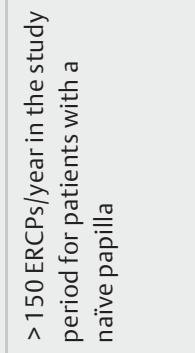 & 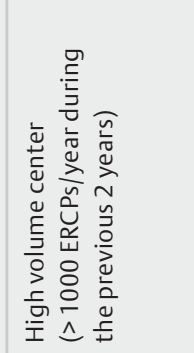 & 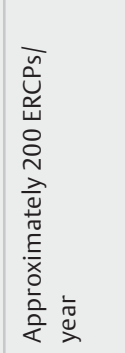 & 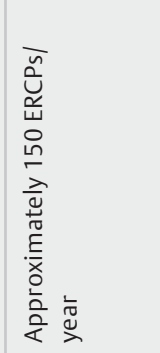 & 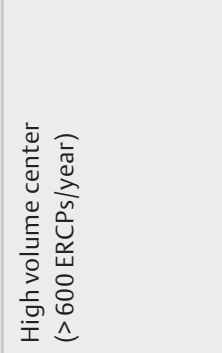 \\
\hline 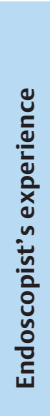 & 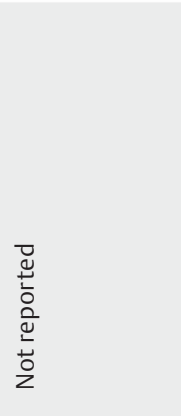 & 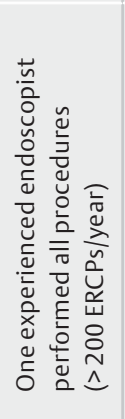 & 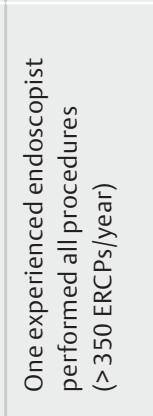 & 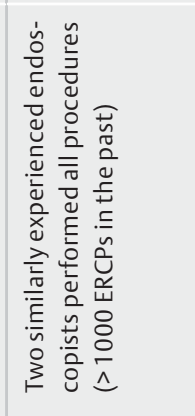 & 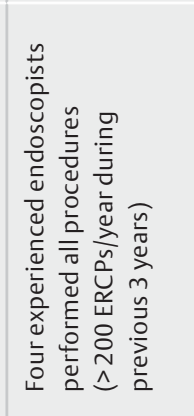 & 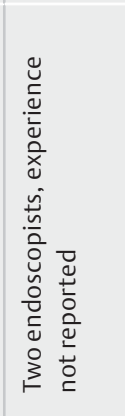 & 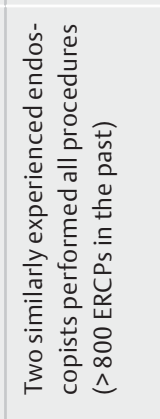 & 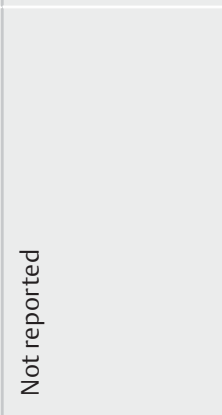 \\
\hline 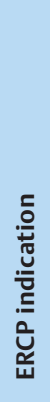 & 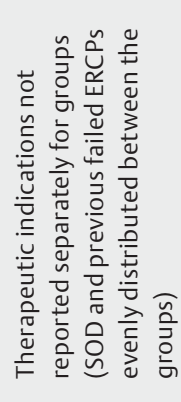 & 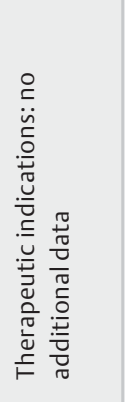 & 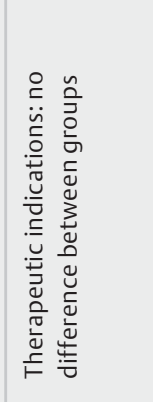 & 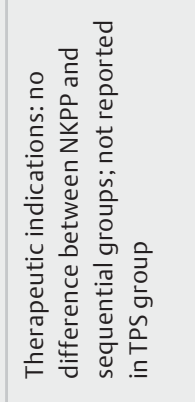 & 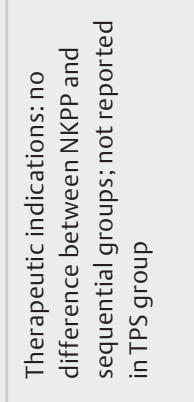 & 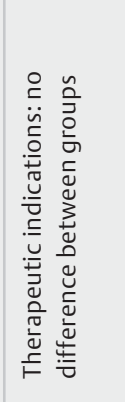 & 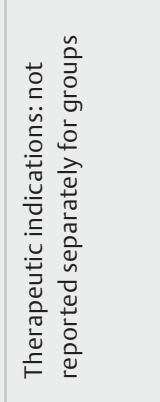 & 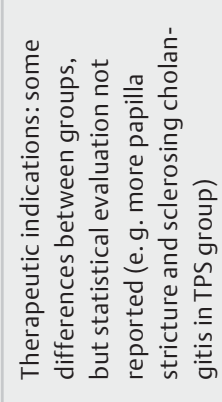 \\
\hline 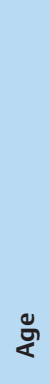 & 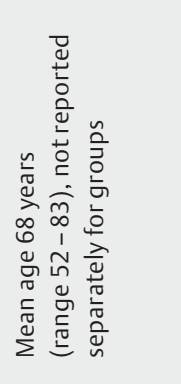 & 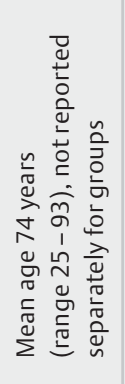 & 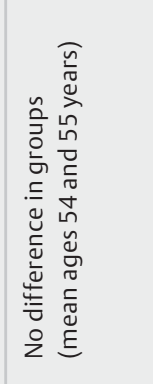 & 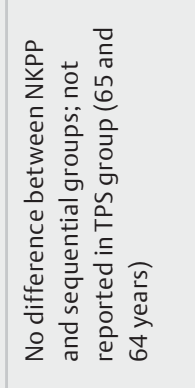 & 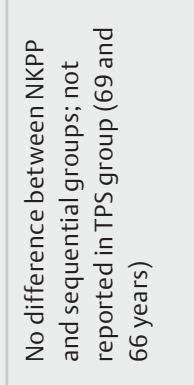 & 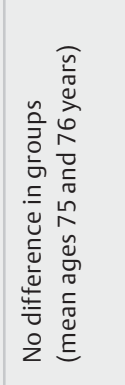 & 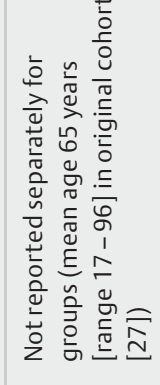 & 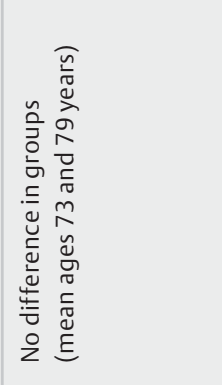 \\
\hline$\hat{\omega}$ & 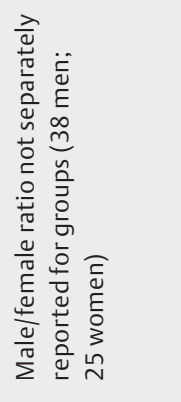 & 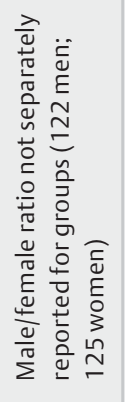 & 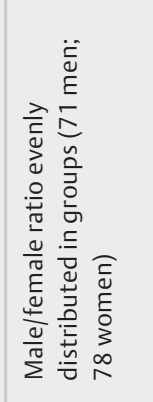 & 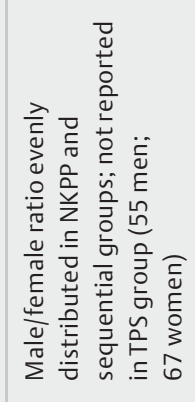 & 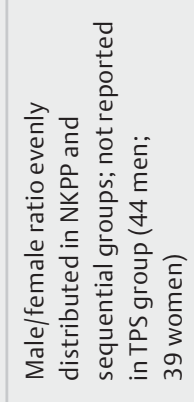 & 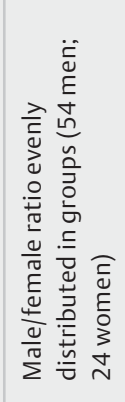 & 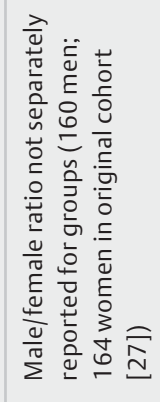 & 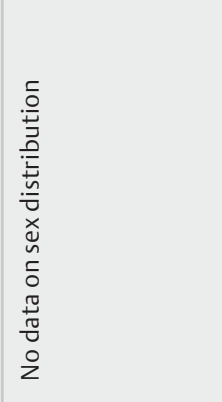 \\
\hline 蛋 & 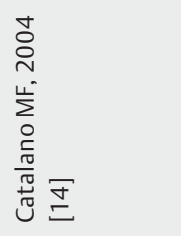 & 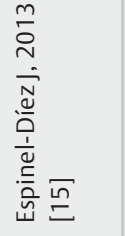 & 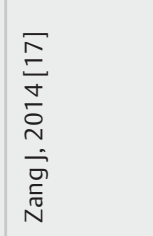 & 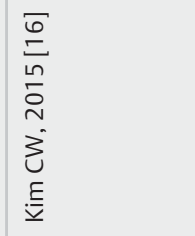 & 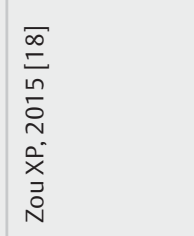 & 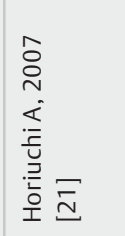 & 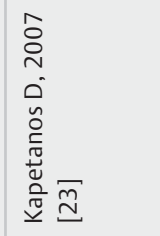 & 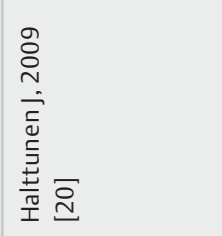 \\
\hline
\end{tabular}




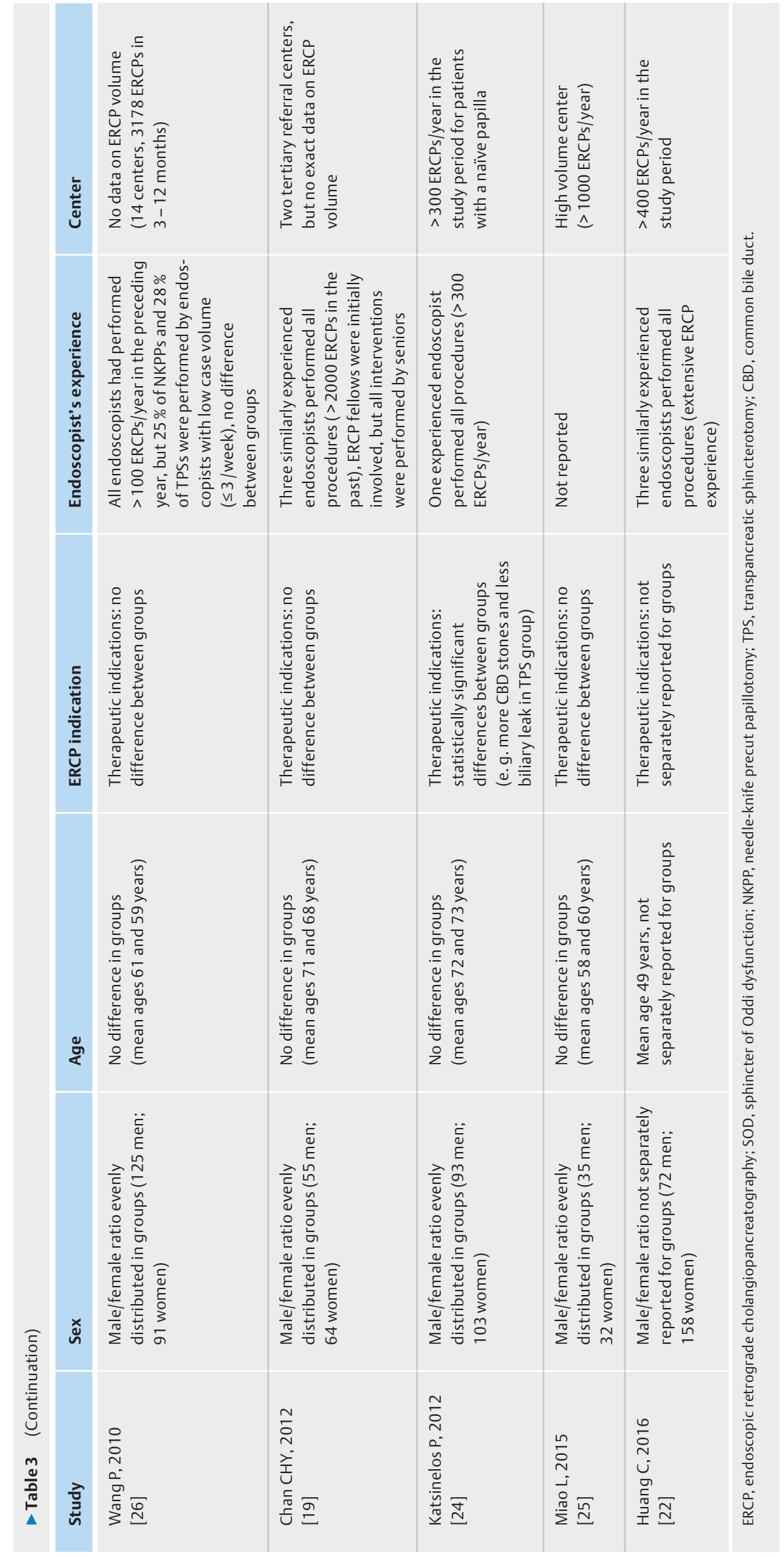


- Table 4 Relative risk (RR) calculations for success rates in the needle-knife precut papillotomy (NKPP) and transpancreatic biliary sphincterotomy (TPS) groups.

\begin{tabular}{|c|c|c|c|c|}
\hline Comparison & Included studies & $\mathbf{R R}^{1}$ & $95 \% \mathrm{Cl}$ & $P$ value \\
\hline \multirow[t]{3}{*}{ Success rate } & All & 0.92 & $0.85-0.99$ & $0.03^{2}$ \\
\hline & Prospective & 0.87 & $0.82-0.94$ & $<0.001$ \\
\hline & Non-sequential & 0.92 & $0.85-1.00$ & 0.047 \\
\hline \multirow[t]{3}{*}{ PEP rate } & All & 0.80 & $0.58-1.11$ & 0.19 \\
\hline & Prospective & 0.51 & $0.27-0.97$ & 0.04 \\
\hline & Non-sequential & 0.93 & $0.63-1.37$ & 0.72 \\
\hline \multirow[t]{3}{*}{ Bleeding rate } & All & 2.18 & $1.15-4.13$ & 0.02 \\
\hline & Prospective & 1.01 & $0.32-3.16$ & 0.98 \\
\hline & Non-sequential & 2.40 & $1.25-4.60$ & 0.008 \\
\hline \multirow[t]{3}{*}{ Total complication rate } & All & 1.17 & $0.72-1.78$ & 0.47 \\
\hline & Prospective & 0.61 & $0.36-1.02$ & 0.06 \\
\hline & Non-sequential & 1.33 & $0.96-1.83$ & 0.08 \\
\hline \multicolumn{5}{|c|}{$\begin{array}{l}\mathrm{Cl} \text {, confidence interval; PEP, post-endoscopic retrograde cholangiopancreatography pancreatitis. } \\
{ }^{1} \mathrm{RR}<1 \text { indicates a lower rate in the NKPP group. } \\
{ }^{2} \text { Numbers in bold represent statistically significant differences. }\end{array}$} \\
\hline
\end{tabular}

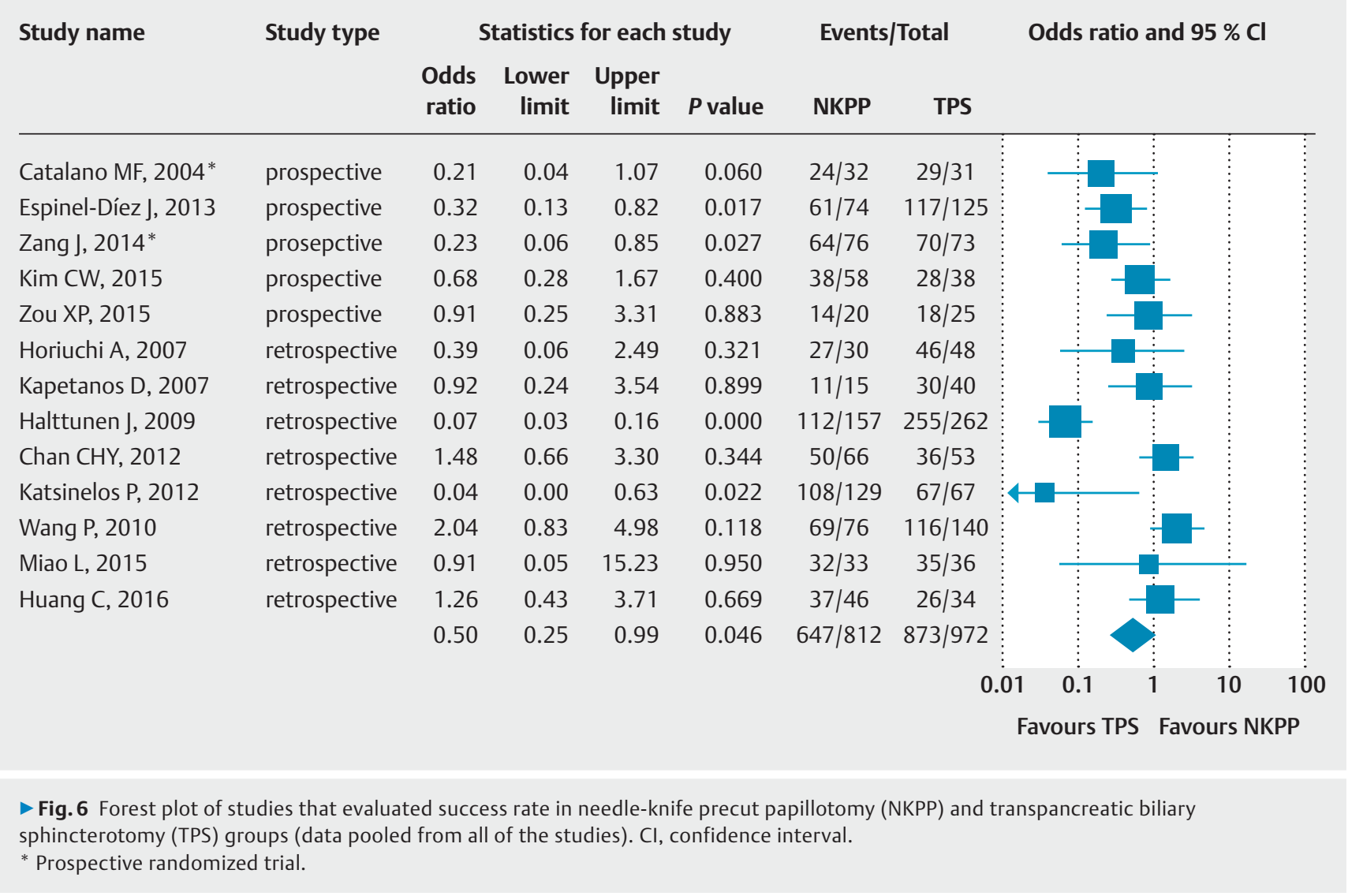




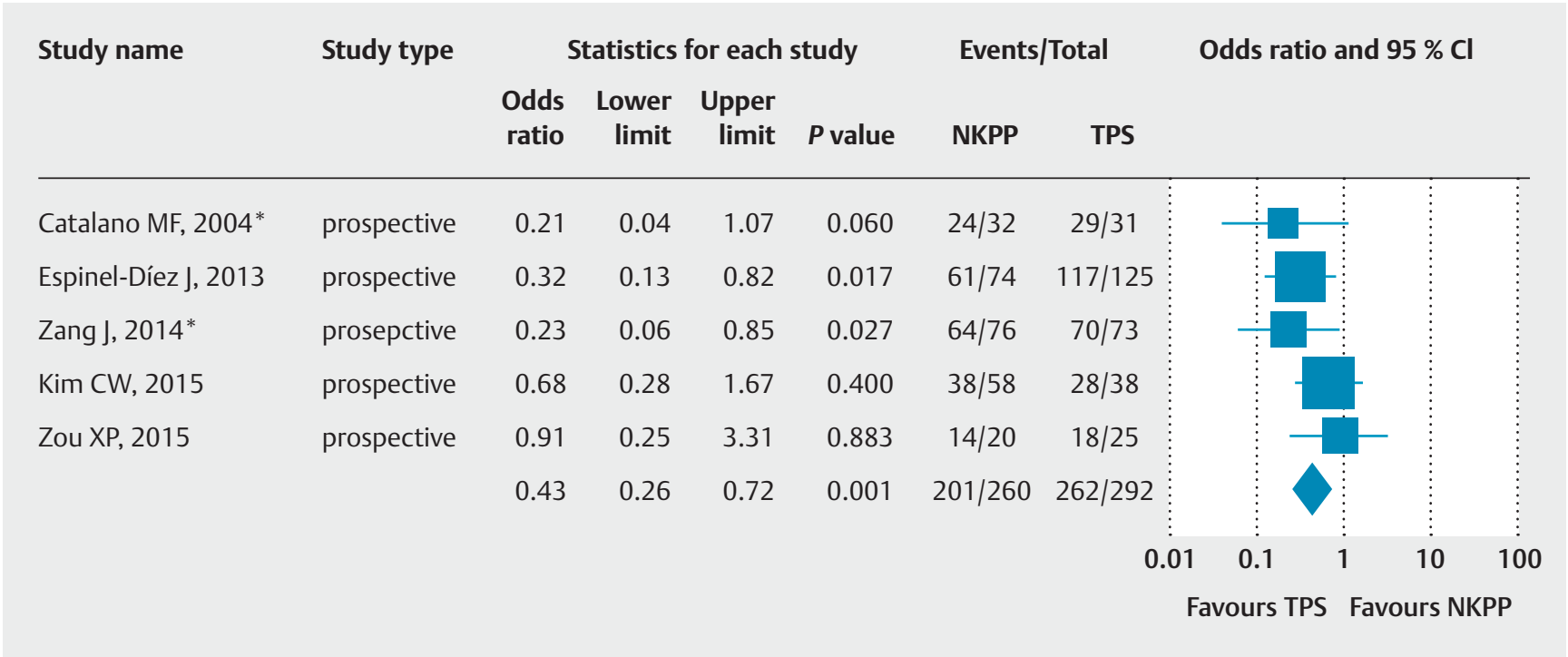

- Fig. 7 Forest plot of studies that evaluated success rate in needle-knife precut papillotomy (NKPP) and transpancreatic biliary sphincterotomy (TPS) groups (data pooled from the prospective studies). Cl, confidence interval.

* Prospective randomized trial.

two methods did not reach the level of statistical significance, but a tendency toward inferiority of the NKPP technique could be seen (OR 0.45, $95 \% \mathrm{Cl} 0.20-1.02 ; P=0.06 ; \mathrm{n}=734$ vs. $909 ; \mathrm{Q}$ $\left.=49.18, \mathrm{df}(\mathrm{Q}) 10 ; P<0.001 ; P^{2}=79.67 \%\right)$. The RR calculation from these studies revealed a significantly lower success rate in the NKPP group compared with the TPS group (RR 0.92, 95 $\% \mathrm{Cl} 0.85-1.00 ; P=0.047$ ) ( Table 4).

\section{PEP rates}

Only one study found NKPP significantly superior to TPS in terms of PEP rates [16], while the remaining articles found no difference between the two cannulation methods. An analysis of the pooled data did not reveal a statistical difference in PEP rates (OR 0.79, $95 \% \mathrm{Cl} 0.53-1.17 ; P=0.24 ; \mathrm{n}=794$ vs. $939 ; Q=$ 12.07, $\mathrm{df}(\mathrm{Q}) 11 ; P=0.36 ; I^{2}=8.85 \%$ ) ( $\boldsymbol{\text { Fig. }} \mathbf{8}$ ). The difference in PEP rates was close to the level of significance when only the prospective studies [14-17] were analyzed. There was a tendency toward lower PEP rates in the NKPP group (OR 0.49, $95 \% \mathrm{Cl}$ $0.23-1.01 ; P=0.052 ; \mathrm{n}=242$ vs. $265 ; Q=6.947, \mathrm{df}(\mathrm{Q}) 3 ; P=$ $0.07 ; P^{2}=56.82 \%$ ), while the RR calculation showed a significantly lower rate of PEP in this analysis (RR $0.51,95 \% \mathrm{Cl} 0.27-$ 0.97; $P=0.04)$ ( Table 4).

No significant difference was found between the two techniques when the studies with non-sequential design were separately analyzed (OR 0.93, $95 \% \mathrm{Cl} 0.63-1.37 ; P=0.72 ; \mathrm{n}=736$ vs. $\left.901 ; Q=4.96, \mathrm{df}(\mathrm{Q}) 10 ; P=0.89 ; P^{2}=0 \%\right)$.

\section{Bleeding rates}

The bleeding rates after TPS or NKPP did not differ significantly in any of the analyzed studies. Our meta-analysis showed that there is significantly more bleeding after NKPP compared with TPS (OR 2.24, 95\%Cl 1.17-4.31; $P=0.02, \mathrm{n}=745$ vs. 908; $Q=$ 5.21, $\operatorname{df}(Q)$ 9; $P=0.82 ; R=0 \%$ ) ( Fig.9). An analysis of the non-sequential studies showed the same results: NKPP was found to cause significantly more bleeding than TPS (OR 2.48, $95 \% \mathrm{Cl} 1.27-4.84 ; P=0.008 ; n=687$ vs. $870 ; Q=5.21, \mathrm{df}(Q) 9$; $\left.P=0.82 ; I^{2}=0 \%\right)$.

An analysis of the data extracted from the prospective studies [14 - 17] revealed no difference in bleeding rates: OR 1.013, $95 \% \mathrm{Cl} 0.32-3.16 ; P=0.98, \mathrm{n}=239$ vs. $268 ; Q=3.324, \mathrm{df}(\mathrm{Q}) 3 ; P$ $=0.34 ; r^{2}=9.75 \%$.

The RR values for bleeding rate from all the studies, from prospective studies only, and from non-sequential studies showed the same differences ( $\triangleright$ Table 4 ).

\section{Perforation rates}

The perforation rates did not differ significantly in any of the analyzed studies. Altogether, seven perforations were reported after NKPP, while only one occurred after TPS. This difference was not statistically significant in our analysis (RD $0.01,95 \% \mathrm{Cl}$ $0.00-0.02 ; P=0.23 ; \mathrm{n}=812$ vs. $942 ; Q=2.06, \mathrm{df}(\mathrm{Q}) 12 ; P>0.99$; $R^{2}=0 \%$ ). The RD similarly did not show any differences between the groups in the separate analyses of prospective and non-sequential studies.

\section{Total complication rates}

Only one study [16] found that NKPP had significantly fewer total adverse events than TPS; the other studies did not find any differences. Our analysis found no difference between the two methods with regard to the total complication rates (OR 1.22, $95 \% \mathrm{Cl} 0.74-2.00 ; P=0.44 ; \mathrm{n}=794$ vs. $939 ; Q=23.48, \mathrm{df}(\mathrm{Q})$ $\left.11 ; P=0.02 ; P^{2}=53.15 \%\right)$.

Excluding the studies with sequential design revealed a tendency for NKPP to cause more total complications than TPS (OR 1.33, 95\% Cl 0.96-1.83; $P=0.08 ; \mathrm{n}=736$ vs. $901 ; Q=7.88$, $\mathrm{df}(\mathrm{Q}) 10 ; P=0.64 ; P^{2}=0 \%$ ) ( Fig. 10). Calculations of RR, similarly to the OR values, did not show significant differences in the NKPP and TPS groups ( $>$ Table 4 ). 


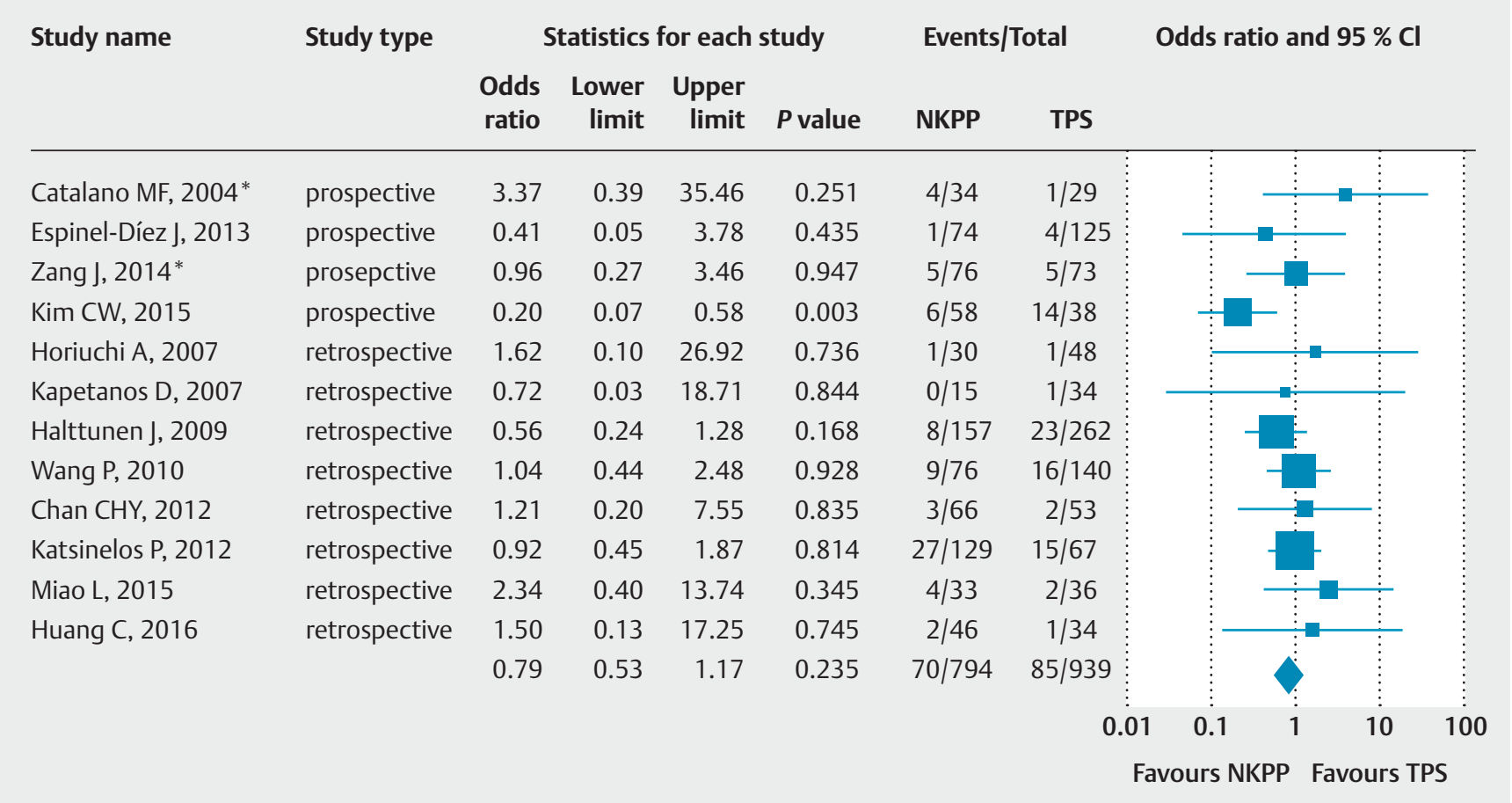

- Fig. 8 Forest plot of studies that evaluated post-endoscopic retrograde cholangiopancreatography pancreatitis (PEP) rate in needle-knife precut papillotomy (NKPP) and transpancreatic biliary sphincterotomy (TPS) groups (data pooled from all of the studies). CI, confidence interval. * Prospective randomized trial.

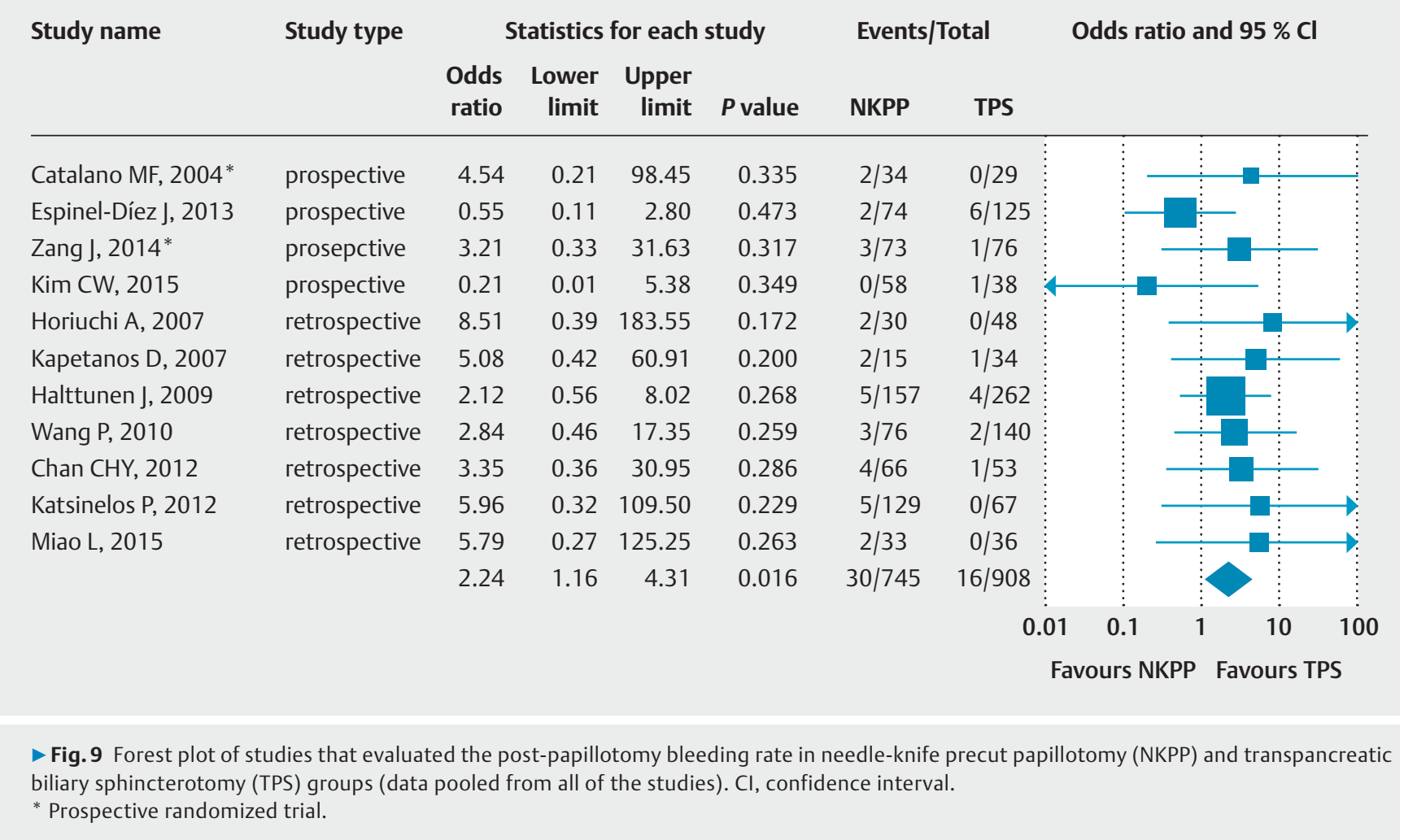




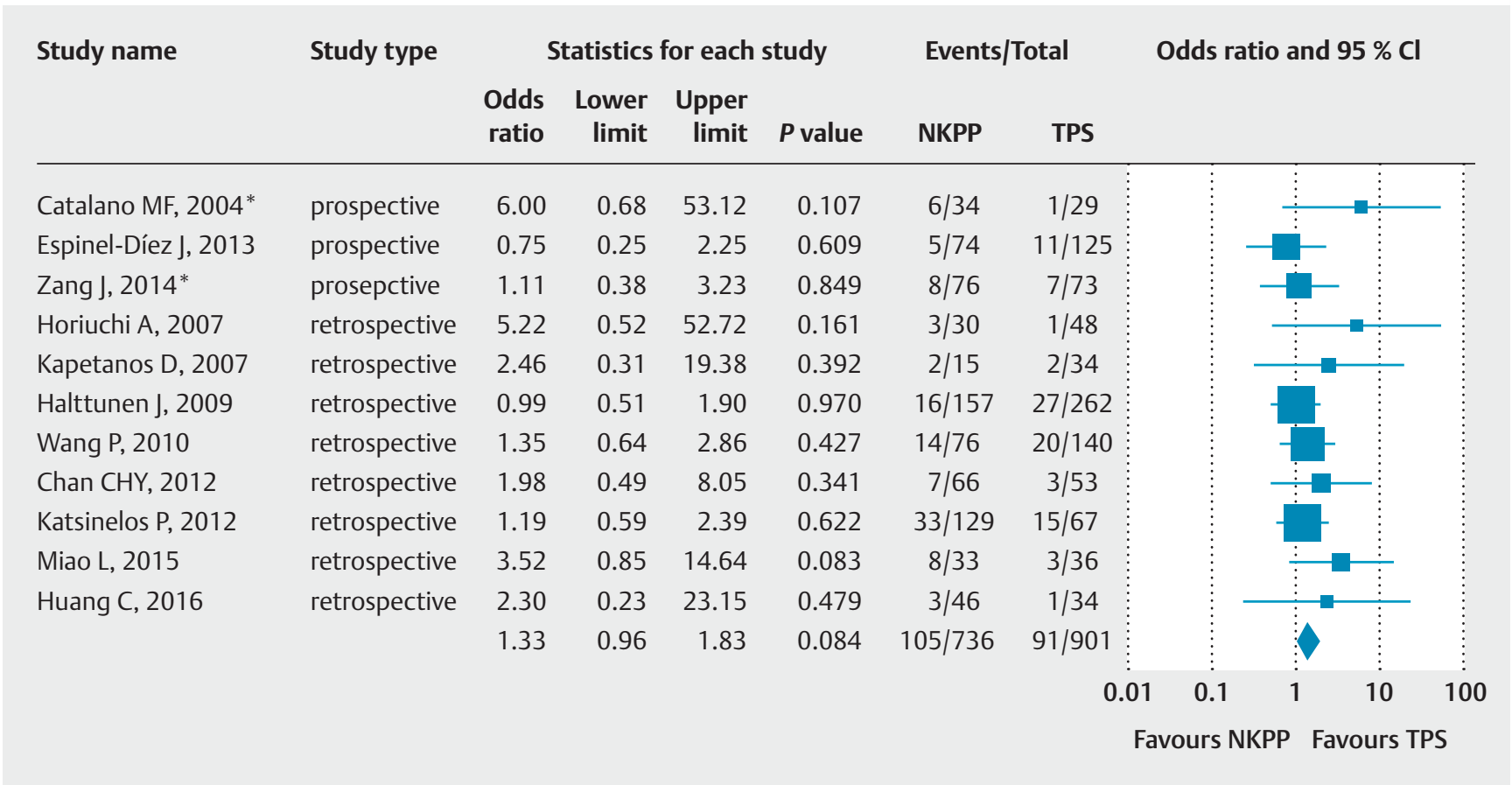

- Fig. 10 Forest plot of studies evaluating total complication rate in needle-knife precut papillotomy (NKPP) and transpancreatic biliary sphincterotomy (TPS) groups (data pooled from prospective and retrospective studies, excluding ones with sequential design). Cl, confidence interval.

\section{Discussion}

Our meta-analysis indicates that TPS is more effective than NKPP with regard to the success of biliary tract cannulation. On the other hand, the PEP rate, the most frequent adverse event after ERCP, did not differ between the TPS and the NKPP groups when all the studies were analyzed together. The PEP rate was lower in the NKPP group in the separate analysis of prospective studies. The bleeding rate was lower after performing TPS in the analysis of all studies, while there was no difference between the bleeding rates of the two techniques if the prospective studies only were analyzed separately. Perforation rates did not differ statistically in the analysis of the two techniques, although only one perforation was observed after TPS in the analyzed studies, while seven perforations occurred after the NKPP technique.

It should be pointed out that TPS is not for novice endoscopists because multiple guidewire insertions or contrast injection into the pancreatic duct, thermal injury during papillotomy, and many other factors can cause PEP. Experienced endoscopists performed the procedures in almost all analyzed studies, which was an important factor in the high rate of cannulation success and low rate of complications. Adherence to the current guidelines regarding the prevention of PEP is also very important after TPS; therefore, insertion of a short $5-\mathrm{Fr}$ pancreatic stent and administration of a non-steroidal suppository are strongly advised in this situation.

No difference in the total complication rates for the two groups was found; however, a significant asymmetry of the funnel plot analysis was detected in this case, which indicates pub- lication bias that could have altered the results. Unfortunately, the less frequent adverse events, like cholangitis, sepsis, and procedure-related death, among others, were not analyzable because most of the studies did not report them. Mean cannulation times, procedure times, and radiation doses during the different cannulation techniques would also be interesting to compare, but these important data were only included in a minority of the studies. An analysis of these parameters, therefore, could not be performed.

We excluded one study that was published only in abstract form from the analysis. The study of Kawaguchi et al. is a retrospective data analysis with small sample size (22 patients with TPS vs. 10 patients with NKPP) [28]. They found no difference between the two techniques regarding cannulation success rate $(P=0.73)$, but NKPP had a significantly higher $P$ EP rate $(P=$ 0.02 ), while the bleeding and total complication rates were not reported.

There are several limitations to this meta-analysis. Firstly, there was significant heterogeneity among the studies with regard to cannulation success and total complication rate. The heterogeneity disappeared when the prospective studies were analyzed separately for cannulation success and when the two studies with sequential design were excluded in the analysis of total complication rate.

Several factors could have caused the heterogeneity among these studies. Difficult biliary access was defined with great variability in the analyzed studies, while other outcome measures were much more uniform. Although the definition of difficult cannulation has not yet been standardized, only the study of Huang et al. [22] fulfilled the criteria that were suggested in 
the recent ESGE guideline [1]. The majority of the studies used a more permissive definition, while two studies $[20,24]$ did not define it ( $\downarrow$ Table 5 ). This theoretically might increase the rate of complications without influencing the success rate. Less heterogeneity was observed in the adverse events. Only the oldest study [14] did not specify how PEP was diagnosed, with all the other studies using the consensus criteria. Bleeding definition was in accordance with the consensus criteria in 10 out of 13 studies; two studies did not specify the definition [20,22]; and another used different criteria [25] ( $\triangleright$ Table 5).

Unfortunately, very few randomized studies that analyze the efficacy and adverse event rates of advanced biliary cannulation methods are available in the literature. Differences in the study design might also have caused heterogeneity. We identified two studies, where TPS was only performed after DGW-assisted biliary access failed $[16,18]$. These sequential attempts at biliary access might increase the rate of successful cannulation, but might also cause more adverse events as more papillary injury is induced this way.

In our analysis, the success rate was not influenced by the inclusion of these sequential studies, because only data from those patients who underwent a TPS attempt were included, while patients in the sequential DGW-TPS group with successful DGW-assisted cannulation were left out. The inclusion or exclusion of sequential studies from the meta-analysis did not influence the two most frequent adverse events: PEP rates were the same, while the bleeding rate was less in the TPS group than in the NKPP group, irrespective of the study design.

Secondly, the majority of the included studies contained retrospective outcome data. We also investigated the prospective studies separately, but the small number of prospective studies may limit the value of this separate analysis. The advantage of TPS in terms of successful cannulation was stronger when the prospective data were analyzed separately and the degree of heterogeneity was much lower. However, with regard to PEP rates, the degree of heterogeneity was higher when the prospective studies were analyzed separately and the RR of PEP favored the NKPP group, while the OR calculation did not show a statistical difference. The bleeding rate was lower in the TPS group than in the NKPP group in the analysis of all studies, but there was no difference in the analysis of the prospective studies, while a low degree of heterogeneity was observed in both analyses. Publication bias may have influenced this outcome because, in the analysis of all studies, a significant asymmetry was detected. However, funnel plot asymmetry and publication bias could not be assessed in the analysis of the prospective studies because of the low number of studies.

Thirdly, some of the analyzed studies did not specify the definition of bleeding after the intervention [20,22] or used a different definition [25] compared with the consensus criteria ( $\triangleright$ Table 5) [29]. Furthermore, one of the selected studies [14] did not specify whether the consensus criteria were used to define PEP ( $\triangleright$ Table 5) [29]. Despite this heterogeneity, it is not likely that omitting this small number of studies from the final analysis would have altered our results.

The studies in our analysis were also heterogeneous with regard to the prophylaxis of PEP ( been worth comparing PEP rates between subgroups where prophylactic measures were applied and those subgroups where no prophylaxis was given but, unfortunately, we could not extract sufficient data for such an analysis. Recent guidelines strongly recommend attempting prophylactic pancreatic stent (PPS) insertion in all patients who have had PGW-assisted methods used for biliary cannulation, along with routine rectal administration of diclofenac or indomethacin in all patients without a contraindication $[1,30]$. Some of the studies were conducted before these guidelines were published, and PPS was not used uniformly in cases when the pancreatic duct was manipulated. Furthermore, no information was found on the administration of non-steroidal anti-inflammatory medication in these studies, which can also influence the rate of PEP. The outcome of the studies regarding this adverse event might have been different if these preventive measures had been uniformly applied ( $>$ Table 5 ).

If there is unintended PGW insertion or pancreas cannulation, the endoscopist can choose to continue directly with TPS or any of the precut techniques (NKPP or NKF), or to continue guidewire-assisted cannulation with a second guidewire (DGW). The latter possibility is seemingly less invasive than TPS or the precut techniques. Only two studies $[16,18]$ in this meta-analysis used DGW before TPS was attempted, and the rate of successful biliary access was similar to the NKPP group where the pancreatic duct was not accessed. A recent meta-analysis also showed that DGW does not improve biliary access but, on the other hand, almost doubles the risk of PEP where cannulation is difficult (RR 1.98, 95\%Cl 1.14-3.42) [31].

According to our best knowledge, the three remaining options in this situation (TPS, NKPP, and NKF) have not yet been compared in any prospective studies. Based on this meta-analysis, TPS may be better than NKPP, but it is hard to tell whether NKF is superior or not. The cutting can be controlled more easily during TPS than in the freehand technique of NKF (or NKPP), because the position of the papillotome is stabilized by the PGW. This might prevent bleeding and perforation, while the risk of PEP can be reduced by PPS insertion.

It would be interesting to compare TPS and NKF as these two methods are recommended after failed PGW-assisted biliary cannulation in the ESGE guideline [1], but only a few articles that studied these two techniques alongside each other were identified during our search. Lee et al. [32] did not show any difference in success or adverse event rates between the two techniques in their study. The patients were not randomized and fistulotomy was attempted only in a small proportion of patients $(n=19)$ when the pancreatic duct was not accessible. Horiuchi et al. [21] selected the different cannulation methods based on the morphology of the major papilla. They applied the NKPP technique in patients with a large papillary tract with a $90 \%$ success rate. The NKF technique was carried out when a swollen papilla was identified (only in eight patients); the biliary cannulation success rate was $100 \%$, without any complications. TPS, on the other hand, was used in patients with a small papillary tract and was successful in 48 patients (96\%), with one case of pancreatitis. In the study by Katsinelos et al. [24], NKPP, TPS, and NKF were all compared. NKF had a $92 \%$ initial 
- Table 5 Definitions of difficult biliary access and of the possible complications that were used in the included studies.

\begin{tabular}{|c|c|c|c|c|}
\hline Study & Difficult biliary access & PEP & Bleeding & PEP prophylaxis \\
\hline $\begin{array}{l}\text { Catalano MF, } 2004 \\
{[14]}\end{array}$ & $\begin{array}{l}\text { Cannulation was unsuccessful after } \\
\text { more than } 30 \text { minutes } \\
\text { and/or the pancreatic duct had been } \\
\text { injected multiple times }\end{array}$ & Not defined & $\begin{array}{l}\text { Consensus } \\
\text { criteria }\end{array}$ & $\begin{array}{l}\text { PPS in some of the patients, } \\
\text { drugs were not used }\end{array}$ \\
\hline $\begin{array}{l}\text { Espinel-Díez ], } 2013 \\
\text { [15] }\end{array}$ & $\begin{array}{l}\text { More than five failed attempts to } \\
\text { selectively cannulate the bile duct }\end{array}$ & $\begin{array}{l}\text { Consensus } \\
\text { criteria }\end{array}$ & $\begin{array}{l}\text { Consensus } \\
\text { criteria }\end{array}$ & Neither PPS nor drugs were used \\
\hline Zang J, 2014 [17] & $\begin{array}{l}\text { Standard cannulation was unsuccessful } \\
\text { within } 10 \text { minutes } \\
\text { and/or pancreatic duct insertion was } \\
\text { attempted five times }\end{array}$ & $\begin{array}{l}\text { Consensus } \\
\text { criteria }\end{array}$ & $\begin{array}{l}\text { Consensus } \\
\text { criteria }\end{array}$ & Neither PPS nor drugs were used \\
\hline Kim CW, 2015 [16] & $\begin{array}{l}10 \text { unsuccessful attempts to selectively } \\
\text { cannulate the bile duct }\end{array}$ & $\begin{array}{l}\text { Consensus } \\
\text { criteria }\end{array}$ & $\begin{array}{l}\text { Consensus } \\
\text { criteria }\end{array}$ & $\begin{array}{l}\text { PPS after TPS in the latter half of } \\
\text { the study, drugs were not used }\end{array}$ \\
\hline Zou XP, 2015 [18] & $\begin{array}{l}\text { Cannulation could not be accomplished } \\
\text { by more than two experts } \\
\text { cannulation time }>30 \text { minutes } \\
\text { and more than five accidental pancreatic } \\
\text { duct passages }\end{array}$ & $\begin{array}{l}\text { Consensus } \\
\text { criteria }\end{array}$ & $\begin{array}{l}\text { Consensus } \\
\text { criteria }\end{array}$ & $\begin{array}{l}\text { PPS in some of the patients } \\
\text { (suspected SOD, multiple } \\
\text { contrast injection), drugs were } \\
\text { not used }\end{array}$ \\
\hline $\begin{array}{l}\text { Horiuchi A, } 2007 \\
\text { [21] }\end{array}$ & $\begin{array}{l}>15 \text { minutes } \\
\text { and/or the pancreatic duct had been } \\
\text { injected/opacified multiple times }\end{array}$ & $\begin{array}{l}\text { Consensus } \\
\text { criteria }\end{array}$ & $\begin{array}{l}\text { Consensus } \\
\text { criteria }\end{array}$ & Neither PPS nor drugs were used \\
\hline $\begin{array}{l}\text { Kapetanos D, } 2007 \\
\text { [23] }\end{array}$ & $\begin{array}{l}>10 \text { attempts to selectively cannulate the } \\
\text { bile duct }\end{array}$ & $\begin{array}{l}\text { Consensus } \\
\text { criteria }\end{array}$ & $\begin{array}{l}\text { Consensus } \\
\text { criteria }\end{array}$ & $\begin{array}{l}\text { No PPS, pentoxifylline in some } \\
\text { patients (no effect of pentoxi- } \\
\text { fylline on pancreatitis rates was } \\
\text { shown in the original study [27]) }\end{array}$ \\
\hline $\begin{array}{l}\text { Halttunen ], } 2009 \\
{[20]}\end{array}$ & Not defined & $\begin{array}{l}\text { Consensus } \\
\text { criteria }\end{array}$ & Not defined & $\begin{array}{l}\text { PPS in a small number of } \\
\text { patients, drugs were not used }\end{array}$ \\
\hline Wang P, 2010 [26] & $\begin{array}{l}\text { Multiple unsuccessful attempts to selectively } \\
\text { cannulate the bile duct }\end{array}$ & $\begin{array}{l}\text { Consensus } \\
\text { criteria }\end{array}$ & $\begin{array}{l}\text { Consensus } \\
\text { criteria }\end{array}$ & $\begin{array}{l}\text { PPS in a small number of } \\
\text { patients, drugs were not used }\end{array}$ \\
\hline $\begin{array}{l}\text { Chan CHY, } 2012 \\
\text { [19] }\end{array}$ & At the discretion of the endoscopist & $\begin{array}{l}\text { Consensus } \\
\text { criteria }\end{array}$ & $\begin{array}{l}\text { Consensus } \\
\text { criteria }\end{array}$ & $\begin{array}{l}\text { PPS in some of the patients, } \\
\text { drugs were not used }\end{array}$ \\
\hline $\begin{array}{l}\text { Katsinelos P, } 2012 \\
\text { [24] }\end{array}$ & Not defined & $\begin{array}{l}\text { Consensus } \\
\text { criteria }\end{array}$ & $\begin{array}{l}\text { Consensus } \\
\text { criteria }\end{array}$ & $\begin{array}{l}\text { PPS and drugs in a small number } \\
\text { of patients }\end{array}$ \\
\hline Miao L, 2015 [25] & $\begin{array}{l}\text { Failing to enter the bile duct but repeated } \\
\text { (more than three times) insertion of the } \\
\text { catheter into the pancreatic duct, a } \\
\text { pancreatic guidewire or plastic stent was } \\
\text { placed, and bile duct cannulation was } \\
\text { attempted again }\end{array}$ & $\begin{array}{l}\text { Consensus } \\
\text { criteria }\end{array}$ & $\begin{array}{l}\text { Vomiting or } \\
\text { black stools } \\
\text { after ERCP } \\
\text { or hemoglobin } \\
<95 \% \text { of normal } \\
\text { level within } 24 \\
\text { hours }\end{array}$ & $\begin{array}{l}\text { All patients had PPS, drugs were } \\
\text { not used }\end{array}$ \\
\hline Huang C, 2016 [22] & $\begin{array}{l}\text { More than five contacts with the papilla } \\
\text { during the attempt to cannulate } \\
>5 \text { minutes attempting to cannulate } \\
\text { or more than one unintentional pancreatic } \\
\text { duct cannulation }\end{array}$ & $\begin{array}{l}\text { Consensus } \\
\text { criteria }\end{array}$ & Not defined & $\begin{array}{l}\text { PPS after repeated cannulation } \\
\text { or injection, indomethacin } \\
\text { suppository in the later phase } \\
\text { of the study }\end{array}$ \\
\hline
\end{tabular}

cannulation success rate (in 78 patients), while TPS was successful in all cases (67 patients). In this study, the overall complication rate and the PEP rate were significantly lower in the NKF group than in the groups managed with the other techniques.
Differences in the timing of TPS or NKPP after failed biliary access can also cause considerable differences in the outcome. A recent meta-analysis showed that early precut can significantly decrease the PEP rate compared with persistent attempts, while not influencing the cannulation rate and overall complication rate [33]. Our meta-analysis showed that, despite 
the time before the precut being variable in the included studies, the biliary cannulation rate with TPS was better and the PEP risk was similar.

Data about the long-term consequences of pancreatic sphincterotomy are scarce. As with biliary sphincterotomy, papillary stenosis can develop following a small incision, and proximal pancreatic duct stricture can also occur [34]. PPS is an important tool to prevent PEP, which is probably the most significant early complication of pancreatic sphincterotomy. Sometimes PPS itself can cause pancreatic duct and parenchymal injury, especially in patients with a normal caliber pancreatic duct [35]. However, the true prevalence of these changes, and therefore the long term clinical significance, is not yet known.

In summary, the present meta-analysis indicates that TPS increases the rate of biliary access compared with NKPP in patients with difficult CBD cannulation. This comes with a decreased frequency of bleeding, but the risk of total adverse events does not differ. These findings might reduce the prejudices against TPS and promote its more frequent application in patients with difficult biliary access, but low volume centers with less expertise in ERCP are not advised to use this technique.

Our suggested algorithm for patients with difficult biliary access would be precut papillotomy (preferably NKF) if a PGW cannot be inserted, or TPS after insertion of a PGW, followed by appropriate PEP prophylaxis. Further prospective multicenter studies are needed to compare the effectiveness and true adverse event rates for TPS and other advanced cannulation techniques when the current recommendations of early precut and prophylactic measures to prevent PEP are uniformly followed.

\section{Acknowledgment}

The present study is dedicated to the 650th anniversary of the founding of the University of Pécs, Hungary.

Funding was provided from Economic Development and Innovation Operative Programme Grant of the National Research, Development and Innovation Office (GINOP-2.3.2-15-201600048).

Competing interests

None

References

[1] Testoni PA, Mariani A, Aabakken L et al. Papillary cannulation and sphincterotomy techniques at ERCP: European Society of Gastrointestinal Endoscopy (ESGE) Clinical Guideline. Endoscopy 2016; 48: $657-683$

[2] Mammen A, Haber G. Difficult biliary access: advanced cannulation and sphincterotomy technique. Gastrointest Endosc Clin N Am 2015; 25: $619-630$
[3] Liao WC, Angsuwatcharakon P, Isayama $\mathrm{H}$ et al. International consensus recommendations for difficult biliary access. Gastrointest Endosc 2017; 85: 295- 304

[4] Goff JS. Long-term experience with the transpancreatic sphincter precut approach to biliary sphincterotomy. Gastrointest Endosc 1999; 50: $642-645$

[5] Kawakami H, Kubota Y, Kawahata S et al. Transpapillary selective bile duct cannulation technique: Review of Japanese randomized controlled trials since 2010 and an overview of clinical results in precut sphincterotomy since 2004. Dig Endosc 2016; 28: 77 - 95

[6] Choudhary A, Winn J, Siddique $S$ et al. Effect of precut sphincterotomy on post-endoscopic retrograde cholangiopancreatography pancreatitis: a systematic review and meta-analysis. World J Gastroenterol 2014; 20: 4093-4101

[7] Moher D, Liberati A, Tetzlaff J et al. Preferred reporting items for systematic reviews and meta-analyses: The PRISMA statement. Ann Int Med 2009; 151: $264-269$

[8] DaVee T, Garcia JA, Baron TH. Precut sphincterotomy for selective biliary duct cannulation during endoscopic retrograde cholangiopancreatography. Ann Gastroenterol 2012; 25: 291 - 302

[9] Jadad AR, Moore RA, Carroll D et al. Assessing the quality of reports of randomized clinical trials: is blinding necessary? Control Clin Trials 1996; 17: $1-12$

[10] Slim K, Nini E, Forestier D et al. Methodological index for non-randomized studies (minors): development and validation of a new instrument. ANZ J Surg 2003; 73: $712-716$

[11] Mantel N, Haenszel W. Statistical aspects of the analysis of data from retrospective studies of disease. J Natl Cancer Inst 1959; 22: 719 - 748

[12] DerSimonian R, Laird N. Meta-analysis in clinical trials. Control Clin Trials 1986; 7: $177-188$

[13] Higgins JPT, Green S, eds. Cochrane Handbook for Systematic Reviews of Interventions. Version 5.1.0 (updated March 2011). The Cochrane Collaboration; 2011: Available from: www.handbook.cochrane.org Accessed: 2 May 2017

[14] Catalano MF, Linder JD, Geenen JE. Endoscopic transpancreatic papillary septotomy for inaccessible obstructed bile ducts: Comparison with standard pre-cut papillotomy. Gastrointest Endosc 2004; 60: $557-561$

[15] Espinel-Díez J, Pinedo-Ramos E, Vaquero-Ayala L et al. Combined precut in difficult biliary cannulation. Revista Esp Enferm Dig 2013; 105: $334-337$

[16] Kim CW, Chang JH, Kim TH et al. Sequential double-guidewire technique and transpancreatic precut sphincterotomy for difficult biliary cannulation. Saudi J Gastroenterol 2015; 21: $18-24$

[17] Zang J, Zhang C, Gao J. Guidewire-assisted transpancreatic sphincterotomy for difficult biliary cannulation: A prospective randomized controlled trial. Surg Laparosc Endosc Percutan Tech 2014; 24: 429433

[18] Zou XP, Leung JW, Li YH et al. Comparison of sequential pancreatic duct guidewire placement technique and needle knife precut sphincterotomy for difficult biliary cannulation. J Dig Dis 2015; 16: 741 - 746

[19] Chan CHY, Brennan FN, Zimmerman M] et al. Wire assisted transpancreatic septotomy, needle knife precut or both for difficult biliary access. J Gastroenterol Hepatol 2012; 27: $1293-1297$

[20] Halttunen J, Keränen I, Udd M et al. Pancreatic sphincterotomy versus needle knife precut in difficult biliary cannulation. Surg Endosc 2009; 23: $745-749$

[21] Horiuchi A, Nakayama Y, Kajiyama $M$ et al. Effect of precut sphincterotomy on biliary cannulation based on the characteristics of the major duodenal papilla. Clin Gastroenterol Hepatol 2007; 5: 1113-1118

[22] Huang C, Kung J, Liu Y et al. Use of double wire-guided technique and transpancreatic papillary septotomy in difficult ERCP: 4-year experience. Endosc Int Open 2016; 4: E1107-E1110 
[23] Kapetanos D, Kokozidis G, Christodoulou D et al. Case series of transpancreatic septotomy as precutting technique for difficult bile duct cannulation. Endoscopy 2007; 39: 802-806

[24] Katsinelos P, Gkagkalis S, Chatzimavroudis G et al. Comparison of three types of precut technique to achieve common bile duct cannulation: A retrospective analysis of 274 cases. Dig Dis Sci 2012; 57: $3286-3292$

[25] Miao L, Li QP, Zhu MH et al. Endoscopic transpancreatic septotomy as a precutting technique for difficult bile duct cannulation. World J Gastroenterol 2015; 21: 3978 -3982

[26] Wang P, Zhang W, Liu F et al. Success and complication rates of two precut techniques, transpancreatic sphincterotomy and needle-knife sphincterotomy for bile duct cannulation. J Gastrointest Surg 2010; 14: $697-704$

[27] Kapetanos D, Kokozidis G, Christodoulou D et al. A randomized controlled trial of pentoxifylline for the prevention of post-ERCP pancreatitis. Gastrointest Endosc 2007; 66: $513-518$

[28] Kawaguchi Y, Mine T. Needle-knife sphincterotomy versus guidewireassisted transpancreatic sphincterotomy for difficult biliary cannulation. J Gastroenterol Hepatol 2015; 30: 225-226

[29] Cotton PB, Lehman G, Vennes J et al. Endoscopic sphincterotomy complications and their management: an attempt at consensus. Gastrointest Endosc 1991; 37: 383-393
[30] Dumonceau JM, Andriulli A, Elmunzer B] et al. Prophylaxis of postERCP pancreatitis: European society of gastrointestinal endoscopy (ESGE) guideline - Updated June 2014. Endoscopy 2014; 46: 799-815

[31] Tse F, Yuan Y, Moayyedi $P$ et al. Double-guidewire technique in difficult biliary cannulation for the prevention of post-ERCP pancreatitis: a systematic review and meta-analysis. Endoscopy 2017; 49: 15-26

[32] Lee Y], Park YK, Lee M] et al. Different strategies for transpancreatic septotomy and needle knife infundibulotomy due to the presence of unintended pancreatic cannulation in difficult biliary cannulation. Gut Liver 2015; 9: 534 - 539

[33] Cennamo V, Fuccio L, Zagari RM et al. Can early precut implementation reduce endoscopic retrograde cholangiopancreatography-related complication risk? Meta-analysis of randomized controlled trials Endoscopy 2010; 42: $381-388$

[34] Buscaglia JM, Kalloo AN. Pancreatic sphincterotomy: technique, indications, and complications. World J Gastroenterol 2007; 13: 4064 4071

[35] Bakman YG, Safdar K, Freeman ML. Significant clinical implications of prophylactic pancreatic stent placement in previously normal pancreatic ducts. Endoscopy 2009; 41: 1095-1098 